\title{
Scuffing mechanisms of EN-GJS 400-15 spheroidal graphite cast iron against a 52100 bearing steel in a PAO lubricated reciprocating contact
}

\author{
*T.J. Kamps ${ }^{\text {a }}$, J.C. Walker ${ }^{\text {a }}$, R.J. Wood ${ }^{\text {a }}$ P.M. Lee ${ }^{\text {b }}$ A.G. Plint ${ }^{c}$

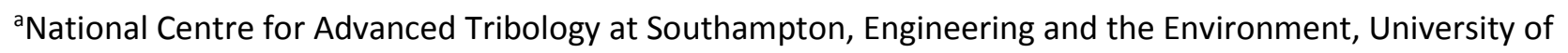 \\ Southampton, Highfield, Southampton SO17 1BJ, UK

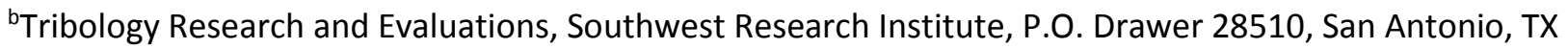 \\ 78238-0510, USA
}

'Phoenix Tribology Ltd, 29A Freemantle House, Kingsclere Park, Kingsclere RG20 4SW, UK

*Corresponding author email address: T.Kamps@soton.ac.uk

Keywords: Automotive, Spheroidal cast iron, High speed friction, Lubrication, Scuffing

\section{Abstract}

Scuffing of the automotive piston ring on liner contact is likely to increase due to engine downsizing and the use of low viscosity engine oils to achieve greater fuel efficiency. This work investigated the scuffing mechanism of EN-GJS 400-15 spheroidal graphite cast iron caused by reciprocating sliding of a 52100 roller bearing element lubricated with PAO base oil.

The contact was conditioned at $100 \mathrm{~N}$ and $15 \mathrm{~Hz}$ over a stroke of $25 \mathrm{~mm}$ at $180{ }^{\circ} \mathrm{C}$. Subsequently the load was incremented in $100 \mathrm{~N} /$ min steps at 5 minute intervals until severe scuffing occurred, indicated by a rapid rise in the average friction coefficient. High speed friction was used to determine the onset of mild and severe scuffing. Stylus and 3D optical profilometery revealed that mild scuffing produced a smooth surface with small cracks compared to the severe scuffed surface which contained adhesive wear craters of $40 \mu \mathrm{m}$ in depth. Focused ion beam cross-sections of the mild scuffed surface and EDS analysis of the microstructure indicated that cracks were initiated by dross inclusions with a similar morphology to flake graphite. The transition to severe scuffing occurred at $700 \mathrm{~N}$ when crack networks facilitated adhesive transfer of cast iron material to the counter-surface.

\section{Introduction}

Increasingly stringent environmental legislation has lead automotive manufacturers to focus engine development on achieving greater fuel efficiency by friction reduction and light-weighting [1], [2]. Decreasing engine mass whilst maintaining the same power output, known a downsizing, minimises the excess energy used to accelerate the drive-train leaving a larger proportion available for useful work. However, increasing an engine's specific output (power output per unit displacement) leads to high combustion pressures and temperatures which are detrimental to the tribological performance of lubricated interfaces in the engine [3].

Engine friction losses differ between combustion cycles and individual engine design, however between 4 and $15 \%$ is typical for diesel engines with $50 \%$ of losses occurring at the piston rings, piston skirt and rod bearing [4]. Viscous losses associated with shearing lubricant films may be reduced by using oil with a lower viscosity, as $80 \%$ of these tribocontacts operate in hydrodynamic and elasto-hydrodynamic regimes [5]. However this also results in the contact surfaces being separated by thinner lubricant films which provides them with less wear protection [3]. 
Contemporary engine designs seek to exploit these two design methodologies by operating on the periphery of the load carrying capacity of thin lubricant films at high temperatures to achieve increased efficiency. This makes them susceptible to occasional adverse changes in operating conditions, which may lead to lubricant film collapse and premature mechanical failure.

The piston ring-liner interface endures a particularly harsh lubrication environment, as although the contact pressures are typically not greater than $70 \mathrm{MPa}$ [3], the temperature, lubricant supply, range of speeds and loading profile can promote lubricant starvation [6]. Wear that occurs during starvation, characterised by macroscopically observable directional modification of the surface morphology may be classified as scuffing, according to the ASTM terminology standard G40 [7]. In many cases scuffing wear is sufficiently severe to modify the surface geometry such that oil consumption and blow-by increase to an unacceptable level resulting in piston seizure [8].

In order to develop piston ring and liner materials with an increased resistance to scuffing wear, a detailed understanding of the mechanism is required. This is challenging as scuffing is a complex multi-stage process with many interdependent variables [9], and the transition from mild wear to seizure occurs in a couple of minutes [10]. Acoustic emissions [11]-[13], electrostatic sensors [9], [14], [15] and high speed friction data [16], [17] have been used to detect the onset and progression of scuffing. The techniques have enabled scuffing wear to be classified into two stages, mild and severe scuffing, which has allowed possible mechanisms to be proposed.

Flake cast iron has been commonly used as a cylinder liner material due to its good mechanical properties, tribological performance and low cost [18]. The increased stress placed on the piston ring cylinder liner contact by engine downsizing requires better performance than it offers. Therefore potential alternative materials including ductile cast iron, compacted cast iron and steels are currently being investigated [19]. Spheroidal cast iron has better tensile and fatigue strengths than flake cast iron whilst retaining good machinability and low manufacturing costs [19]-[21]. The enhancement in material properties are realised by changing the graphite morphology from flakes (angular high aspect ratio inclusions which act as stress raisers) to nodules which reduce the propensity of cracking in the matrix [22], [23]. Consequently specific output can be increased by achieving weight saving through manufacturing cylinder liners with thinner wall thickness to withstand current combustion pressures [19].

Whilst the bulk properties of spheroidal cast iron are preferable, the effect graphite nodules have on tribological performance is dependent on the synergistic effect of the contact conditions on the wear mechanism [23]. Formation of a lubricious graphite film has been a reported mechanism responsible for the good tribological performance of flake cast iron [24]. The graphite film provides protection when there is a transient breakdown in lubricating film. However cracks may form along the sharp graphite lamellar due to fatigue or contact overload [25]. Conversely the aspect ratio of graphite nodules result in less graphite at the surface, consequently an incomplete graphite film forms offering less protection [26]. However the nodules do not act as stress raisers during a contact overload [23], [27]. The present study is concerned with determining the influence that graphite morphology has on the scuffing behaviour of an EN-GJS 400-15 spheroidal cast iron, compared to a flake cast iron structure [17] in a simulated piston ring and cylinder liner contact. Observing the start of mild scuffing using instantaneous friction force measurements allows interruption of sliding at the critical onset of scuffing, facilitating observation of the mechanisms leading to catastrophic adhesive wear through a combination of optical profilometery and focused ion beam/scanning electron microscopy.

\section{Experimental}

In order to simulate a piston ring on liner contact a cylinder on flat geometry was chosen. A $6 \mathrm{~mm}$ diameter 52100 roller bearing element with a G5 surface tolerance, $10 \mathrm{~mm}$ in length including a $0.5 \mathrm{~mm}$ chamfer at 
each end, was used to simulate a piston ring. EN-GJS 400-15 spheroidal graphite cast iron according to BS 2789 was sectioned into flat plate samples and ground at $45^{\circ}$ to the reciprocating direction, $58 \mathrm{~mm} \times 38 \mathrm{~mm}$ x $4 \mathrm{~mm}$.

A transverse section of EN-GJS 400-15 spheroidal cast iron was evaluated using an optical microscope. Standard metallurgical procedures were used to polish the surface to a $1 \mu \mathrm{m}$ diamond finish. Image analysis software was used to measure mean graphite particle diameter from a number of images taken at a magnification of $x 500$.

Vickers hardness measurements of both the cast iron plate and 52100 cylinder were determined in a transverse plane using an indentation load of $10 \mathrm{kgf}$. A minimum of 5 measurements was carried out in order to calculate mean and standard deviation values. Surface topography measurements were performed on both surfaces using a stylus profilometer with a standard $2 \mu \mathrm{m}$ diamond stylus over a data length of $4 \mathrm{~mm}$ and $/ c$ filter cut off length of $0.8 \mathrm{~mm}$. Abbott-Firestone curves were generated for each surface to facilitate comparison of surface peak and valley parameters (Rpk and Rvk) compared at $5 \%$ and $90 \%$ of the bearing area ratio.

Prior to reciprocating sliding tests, both samples were cleaned using petroleum ether in an ultrasonic bath. The roller bearing element was clamped in the reciprocating assembly of a high frequency reciprocating tribometer, perpendicular to the direction of motion, Figure 1. It was loaded against the cast iron plate to form a line contact and reciprocated at a frequency of $15 \mathrm{~Hz}$ over a stroke length of $25 \mathrm{~mm}$. The line contact was lubricated at one of the stroke reversal positions by a needle drip feed. A polyalphaolefin (PAO), viscosity $4 \mathrm{cSt}$ at $100^{\circ} \mathrm{C}$, was passed through the needle at $0.5 \mathrm{ml} / \mathrm{h}$. A synthetic base oil was used to ensure that the experiment focused on the scuffing mechanisms between the two materials and was not compounded with effects caused by additive chemistry.

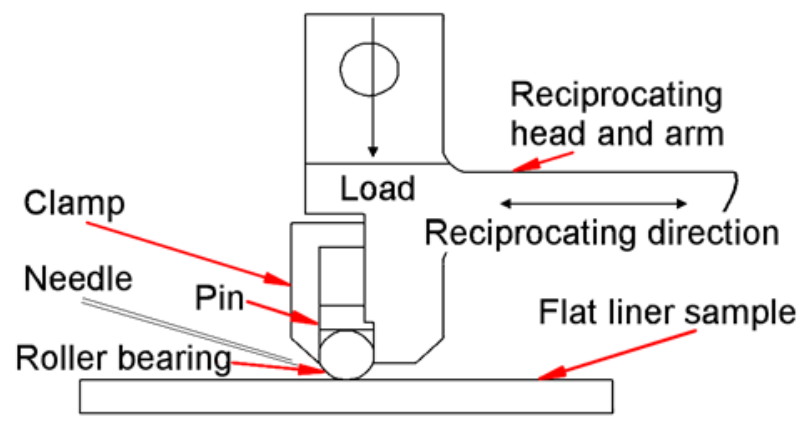

Figure 1 Contact Schematic for the TE-77 high frequency reciprocating tribometer

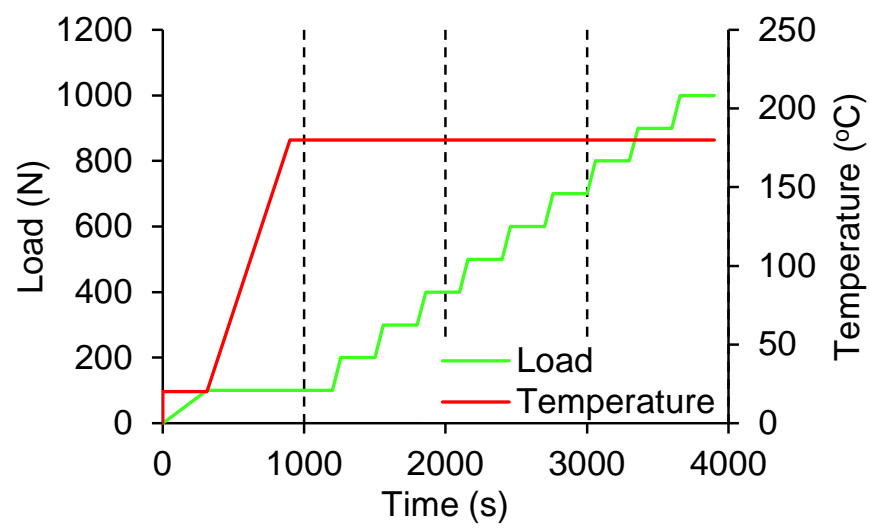

Figure 2 Schematic of the test procedure

The surfaces were conditioned by reciprocating the roller bearing element for $5 \mathrm{~min}$ at $20^{\circ} \mathrm{C}$ with a load increase of $20 \mathrm{~N} / \mathrm{min}$, followed by at temperature ramp of $18^{\circ} \mathrm{C} / \mathrm{min}$ for $10 \mathrm{~min}$ at $100 \mathrm{~N}$ corresponding to a mean initial Hertzian line contact pressure of $180 \mathrm{MPa}$. The contact conditions remained constant for a further 5 min before the first load increment, Figure 2. Subsequently the load was incremented in $100 \mathrm{~N} / \mathrm{min}$ steps at 5 minutes intervals until severe scuffing occurred, indicated by a rapid increase in the average friction coefficient with rate above $0.04 \mathrm{~s}^{-1}$ [25], [28]-[31]. The time averaged contact potential and sample temperature were simultaneously recorded.

The test was repeated in order to determine that the observed transition from mild to severe scuffing was repeatable. Instantaneous high speed friction force and contact potential data was captured in bursts of 
10,000 samples at $10 \mathrm{kHz}$, in order to determine the location of surface damage and lubricant film breakdown along the stroke. Mild scuffing was indicated by an increase in excess of $100 \%$ of the RMS friction force at the stroke reversal positions [17].

The wear scar topographies of the scuffed cast iron liner samples were investigated using a non-contact, variable focal plane microscope. Specific features on the cast iron surface were investigated at higher magnification using a scanning electron microscope (SEM) at $15 \mathrm{kV}$ equipped with energy dispersive $\mathrm{X}$-ray spectroscopy (EDS). A focused ion beam (FIB) microscope was used to selectively remove material from the surface of the cast iron plate in order to investigate changes in the subsurface microstructure induced by scuffing. Site specific cross-sections were made both perpendicular and parallel to the sliding direction and imaged using a combination of electron and ion detection.

\section{Results}

\subsection{Material}

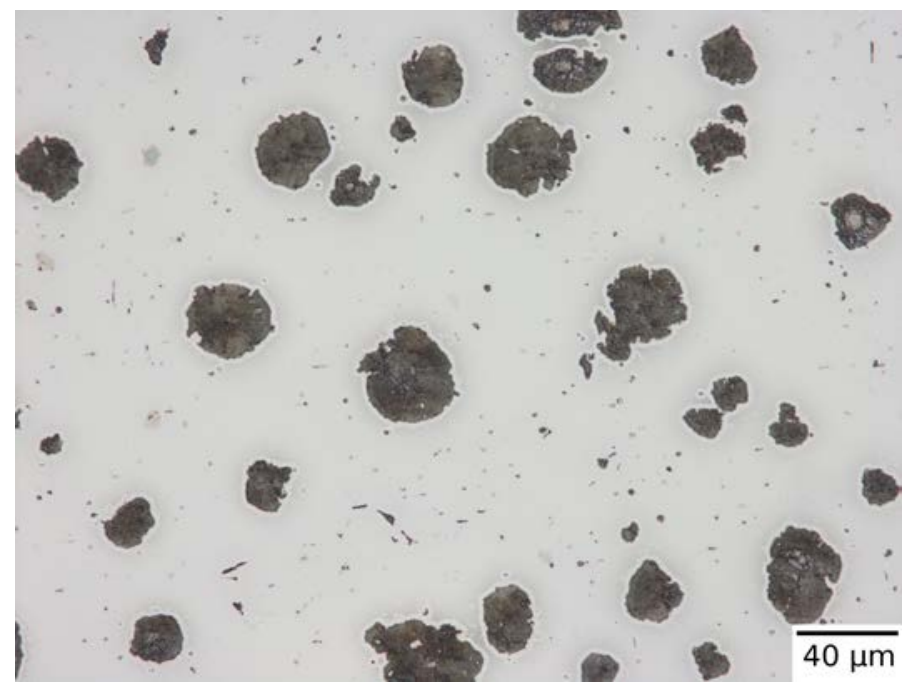

Figure 3. Optical microscope image of the spheroidal cast iron microstructure

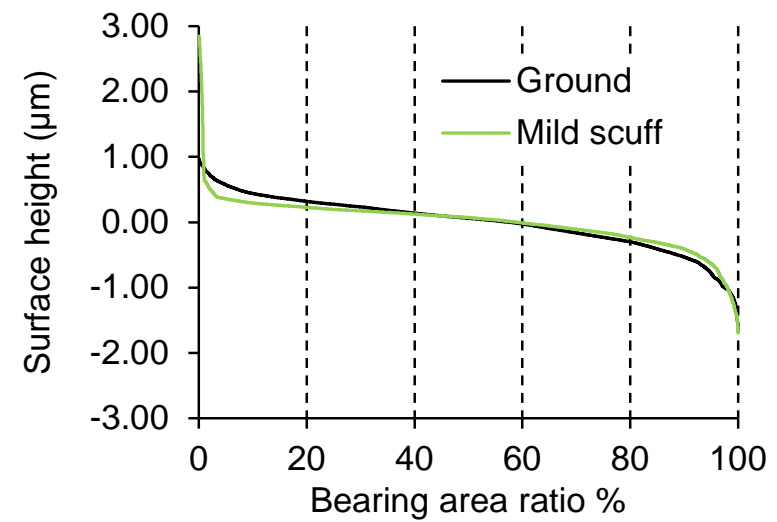

Figure 4 Bearing area curves for the ground and mildscuff surfaces from a Talysurf profilometer (2 $\mu \mathrm{m}$ tip) (expt2)

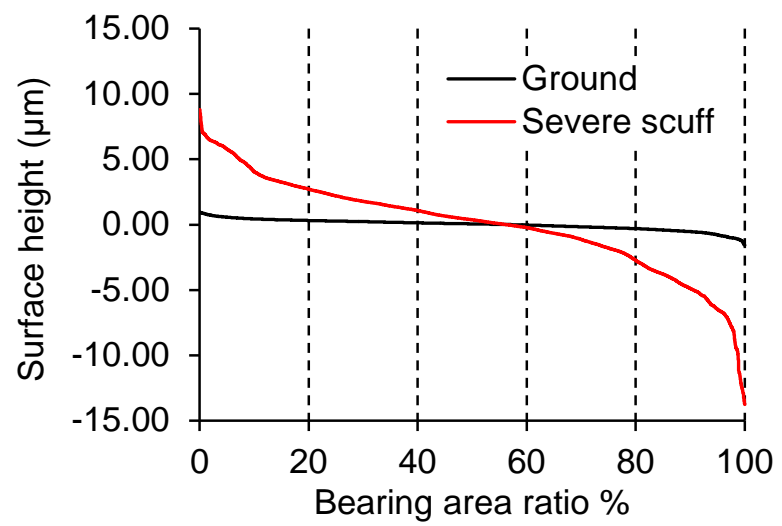

Figure 5 Bearing area curves for the ground and severescuffed surfaces from a Talysurf profilometer ( $2 \mu \mathrm{m}$ tip) (expt2)

Figure 3 shows the polished cross section of the spheroidal cast iron. The size of the graphite spheroids were analysed by counting particles with a size greater than $10 \mu^{2}$ [32]. Particles that crossed the boundary of the image were excluded. $10 \%$ of the image was covered by 32 graphite spheroids with a mean particle area of $303+/-287 \mu \mathrm{m}^{2}$. 
The ground spheroidal cast iron plate had a Vickers hardness of $172+/-3 \mathrm{HV}$ and a surface roughness of $0.346+/-0.013 \mu \mathrm{m}$ measured perpendicular to the direction of grinding. The 52100 roller bearing element had a Vickers hardness of $845+/-4 \mathrm{HV}$ and a surface roughness of $0.041+/-0.009 \mu \mathrm{m}$.

The mild scuff surface had an Ra $0.294+/-0.014 \mu \mathrm{m}$ compared with the severely scuffed surface of 3.247+/$0.324 \mu \mathrm{m}$. The surface roughness, kurtosis, reduced peak height and reduced valley depth for each surface from both experiments were recorded in Table 1. The bearing area ratio curves for ground and mild scuff surface from experiment 2 were plotted in Figure 4; a comparison between the ground severe scuff surfaces is made in Figure 5.

\begin{tabular}{llcccccccc}
\hline Sample & Surface & $\mathbf{R a}$ & $\boldsymbol{\sigma}$ & $\mathbf{R}_{\mathbf{k}}$ & $\boldsymbol{\Sigma}$ & $\mathbf{R}_{\mathbf{p k}}$ & $\boldsymbol{\sigma}$ & $\mathbf{R}_{\mathbf{v k}}$ & $\boldsymbol{\sigma}$ \\
\hline Roller bearing & - & 0.041 & 0.009 & 0.088 & 0.012 & 0.066 & 0.054 & 0.139 & 0.074 \\
& & & & & & & & & \\
Spheroidal & Ground & 0.346 & 0.013 & 1.149 & 0.064 & 0.350 & 0.043 & 0.503 & 0.022 \\
cast iron 1 & Mild & 0.294 & 0.014 & 0.668 & 0.029 & 0.323 & 0.080 & 0.905 & 0.137 \\
& Severe & 3.247 & 0.324 & 8.429 & 1.041 & 3.200 & 0.538 & 5.007 & 1.570 \\
& & & & & & & & & \\
Spheroidal & Ground & 0.340 & 0.030 & 0.940 & 0.059 & 0.302 & 0.036 & 0.681 & 0.062 \\
cast iron 2 & Mild & 0.297 & 0.056 & 0.656 & 0.090 & 0.564 & 0.129 & 0.876 & 0.228 \\
& Severe & 2.602 & 0.186 & 7.822 & 0.731 & 3.114 & 0.788 & 5.095 & 0.425 \\
\hline
\end{tabular}

Table 1 Specimen properties: average surface roughness $\left(R_{a}\right)$, kurtosis $\left(R_{k}\right)$, reduced peak height $\left(R_{p k}\right)$ and reduced valley depth $\left(R_{v k}\right)$ from a Talysurf contact profilometer (standard deviation error, $\left.\sigma\right)$.

\subsection{Friction response}

Friction coefficient, contact potential and load data were plotted against time, Figure 6 . At the running-in load of $100 \mathrm{~N}$ the friction coefficient was 0.10 . The temperature increase to $180^{\circ} \mathrm{C}$ at a constant load of $100 \mathrm{~N}$ resulted in the friction coefficient increasing to 0.14 . Apart from an increase during the $200 \mathrm{~N}$ step, the friction coefficient gradually decreased to 0.08 before it increased rapidly to more than 0.18 during severe scuffing. The repeat test exhibited similar behaviour except for the second half of the running-in period where the friction coefficient decreased for a period of 300 s before returning to the same trend as the initial test, Figure 7. Both tests severely scuffed at a load of $700 \mathrm{~N}$, within $62 \mathrm{~s}$ of each other, a sliding distance of $46.5 \mathrm{~m}, 2 \%$ of the total siding distance of experiment 2 .

High speed friction and contact potential data were recorded at the beginning of the $100 \mathrm{~N}$ running in period (HS1) was plotted against displacement for 15 sequential cycles, Figure 8. The instantaneous friction force had the general form of a square wave and little cyclic variation. The contact potential fluctuated with the stroke position and between each cycle, and appears at a greater magnitude at one end of the stroke initially. Instantaneous friction force and contact potential data were also obtained at the start of the final load step (HS2) and during the severe scuffing failure (HS3). At the start of the final load step (HS2) the friction data continued to take the form of a square wave however there were local increases in friction force at the stroke reversal positions, Figure 9. The reciprocating sample travelled anticlockwise around the friction loop consequently the increase was greatest in the decelerating direction. The contact potential remained close to zero across the entire stroke. Both tests produced a similar friction trace at this stage of the experiment.

During severe scuffing the friction force increased during each stroke, Figure 10. At the onset of severe scuffing the increase in friction force occurred locally on the accelerating side of the stroke reversal position which increased to match the decelerating side. The entire magnitude of the friction force trace then increased. During the last cycles the friction force signal became very disordered and at stroke position 7 $\mathrm{mm}$ the friction force increased locally in the accelerating direction. The contact potential remained close to zero in both directions, with small variations. 


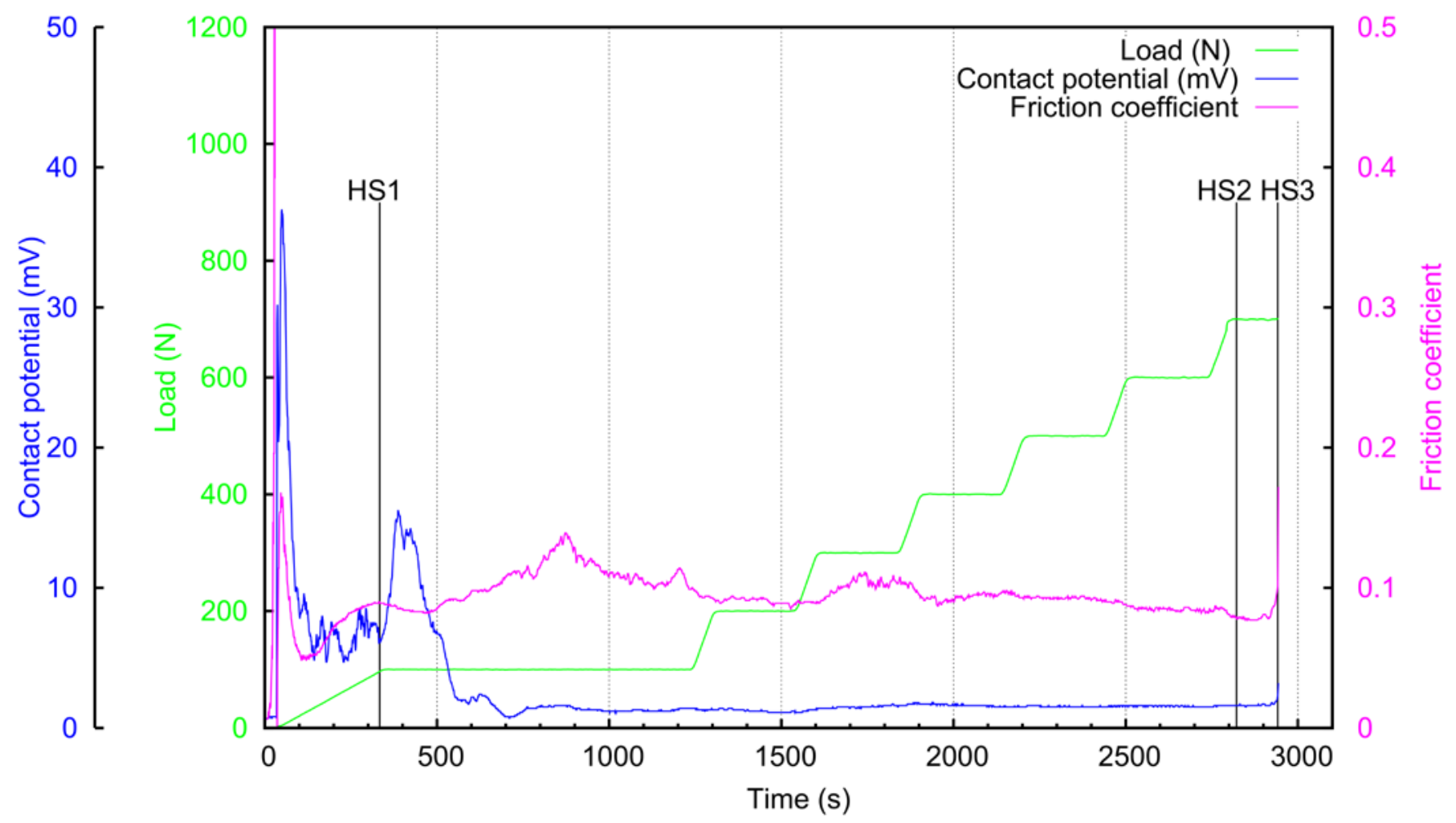

Figure 6 Average friction, normal load, temperature and contact potential plotted against time (experiment 1)

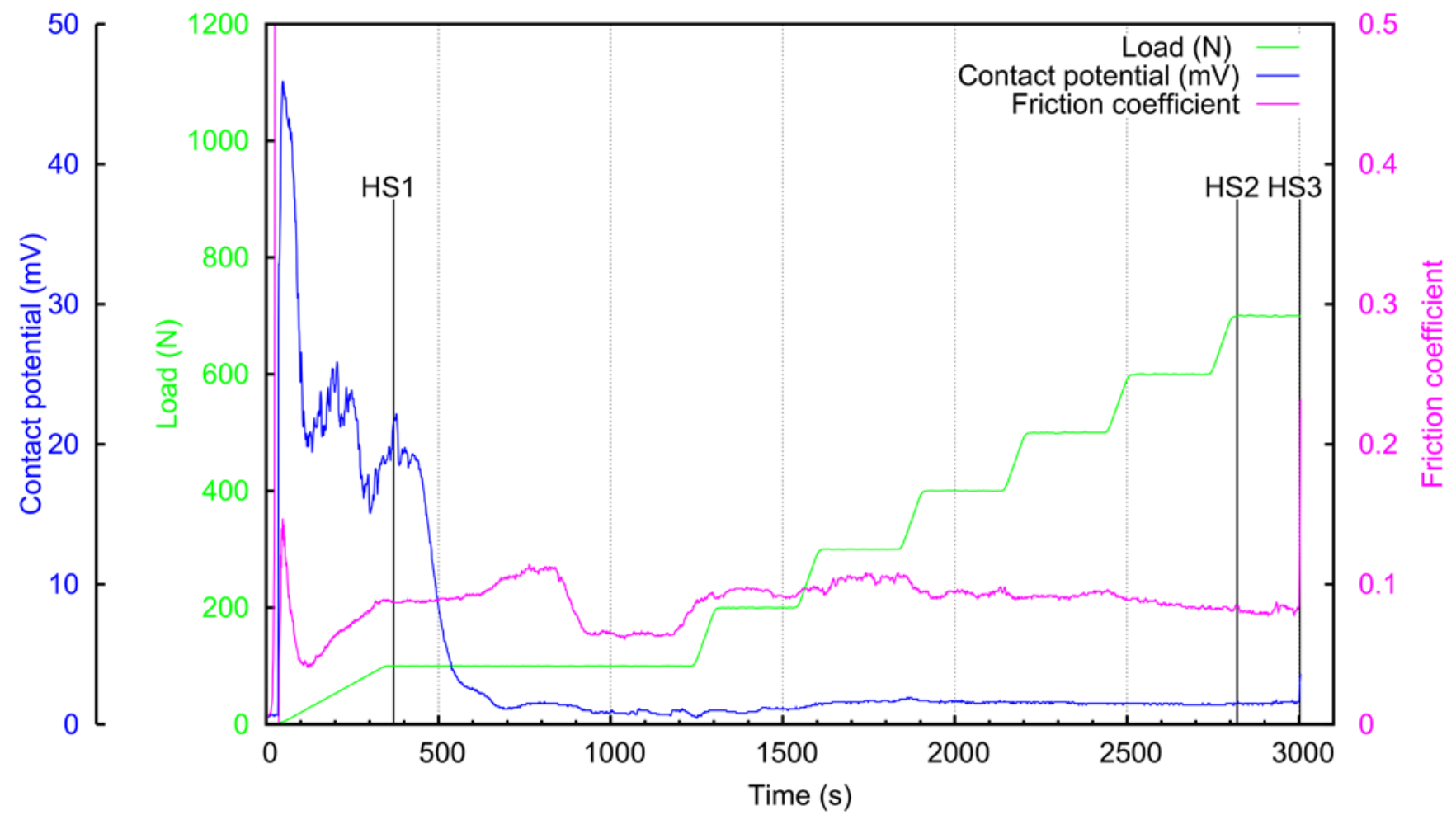

Figure 7 Average friction, normal load, temperature and contact potential plotted against time (experiment 2) 


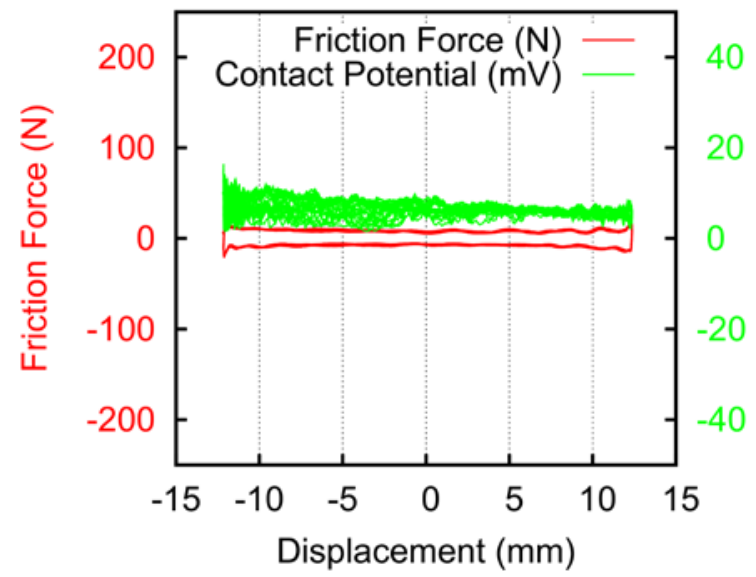

Figure 7 Friction force and contact potential data at start of the running in period

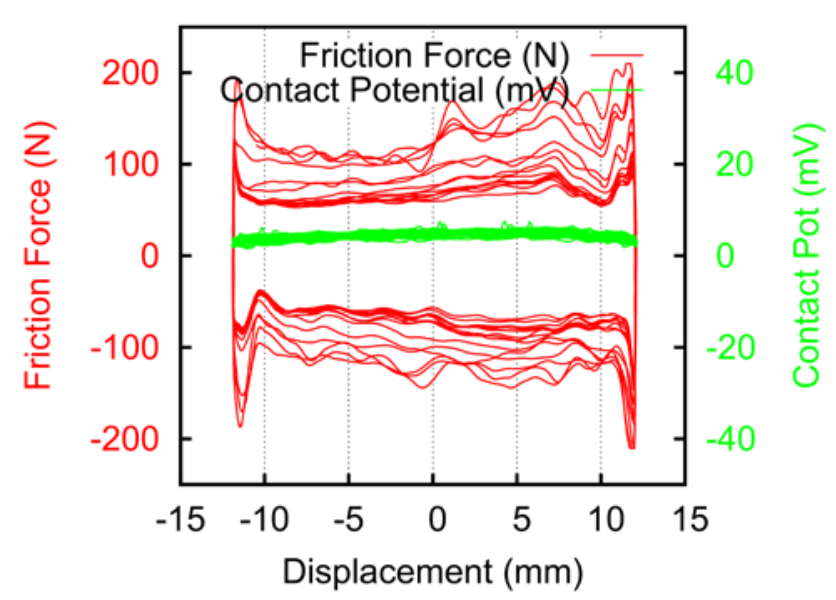

Figure 9 Friction force and contact potential data during severe scuffing failure

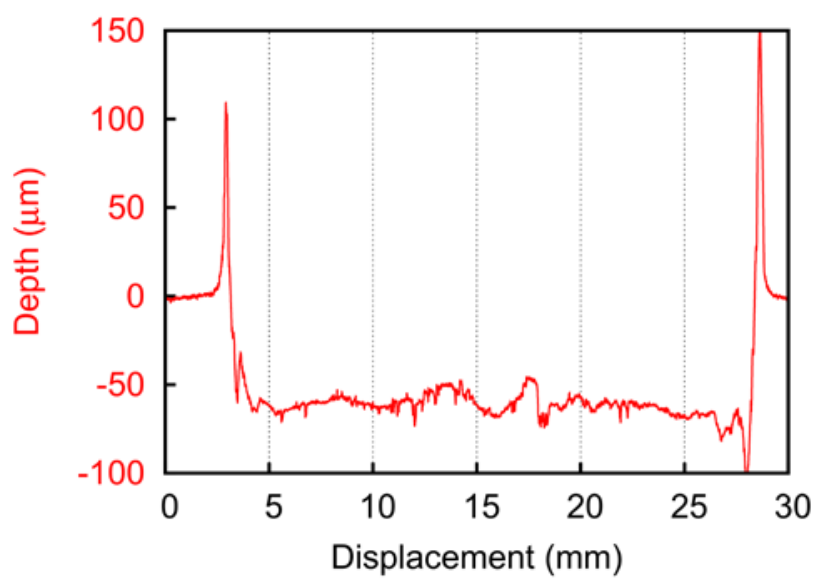

Figure 11 Longitudinal profile of the severe scuffed wear scar

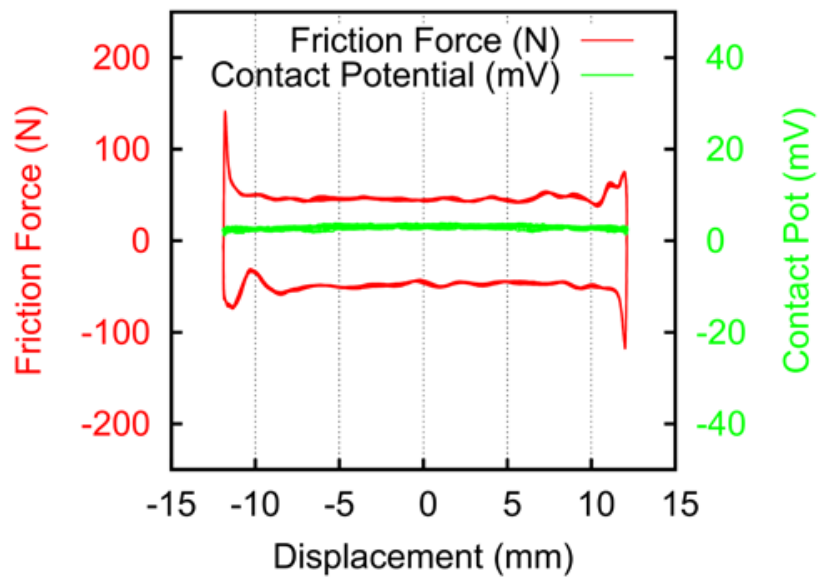

Figure 8 Friction force and contact potential data during mild scuffing at the start of the failure load step

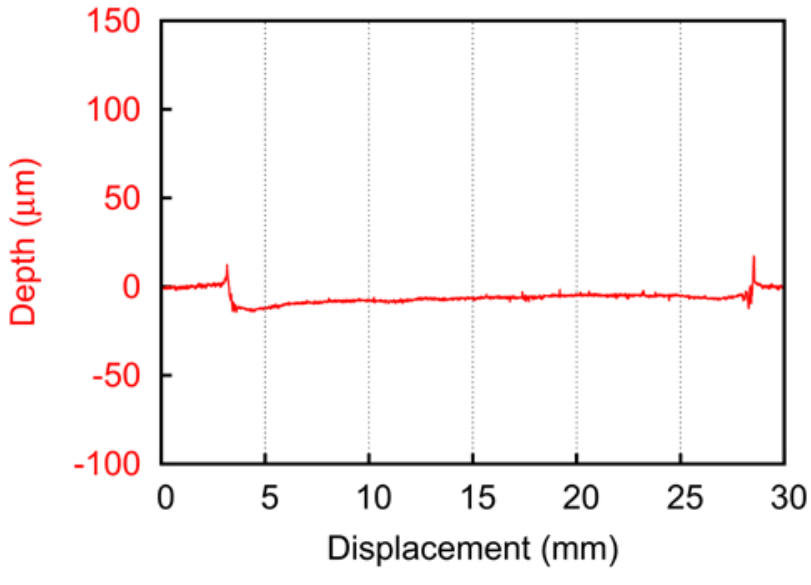

Figure 10 Longitudinal profile of the mild scuffed wear scar

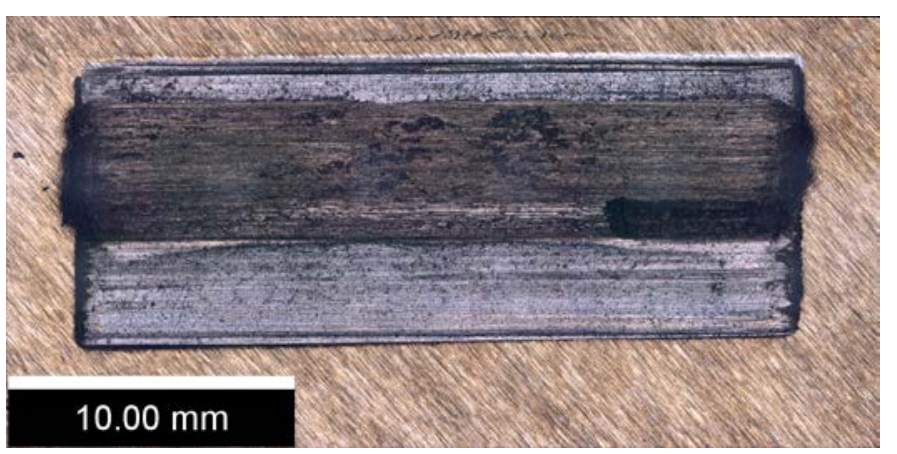

Figure 12 Optical image of the cast iron wear scar from experiment 2 


\subsection{Surface analysis}

\subsubsection{Stylus profilometery}

Longitudinal profiles of the mild and severe scuffed regions of cast iron are shown in Figures 11 and 12 . The mild wear scar profiles from both experiments had a low apparent roughness and shallow wear scar depth, 15-20 $\mu \mathrm{m}$ for the repeat and 20-30 $\mu \mathrm{m}$ for the initial test. Agglomerated material was found on the ground surfaces outside the ends of each wear scar. The ends of the wear scar were rougher than the rest of the scar. The severe wear scar profiles had a high apparent roughness and a wear scar depth approximately three times deeper than the mild scar. The corresponding material agglomerations outside the wear scar were several orders of magnitude larger than in the mild case.

\subsubsection{Optical Profilometery}

The rectangular wear scar on the cast iron sample, shown in Figure 13, had light and dark regions which corresponded to the mild and severe scuffed regions, respectively. The mildly scuffed surface was formed of platelets which had structures observable at the millimetre and micron length scales, Figures 14 and 15 and showed two distinct edges where material was peeled from the surface. There were three instances of platelets which were in the process of being removed and had been folded back on to the material surface. In contrast the severely scuffed surfaces had much greater topographical relief with surface craters up to 40 $\mu \mathrm{m}$ in depth overlaid with scoring marks in the direction of sliding, Figures 16 and 17.

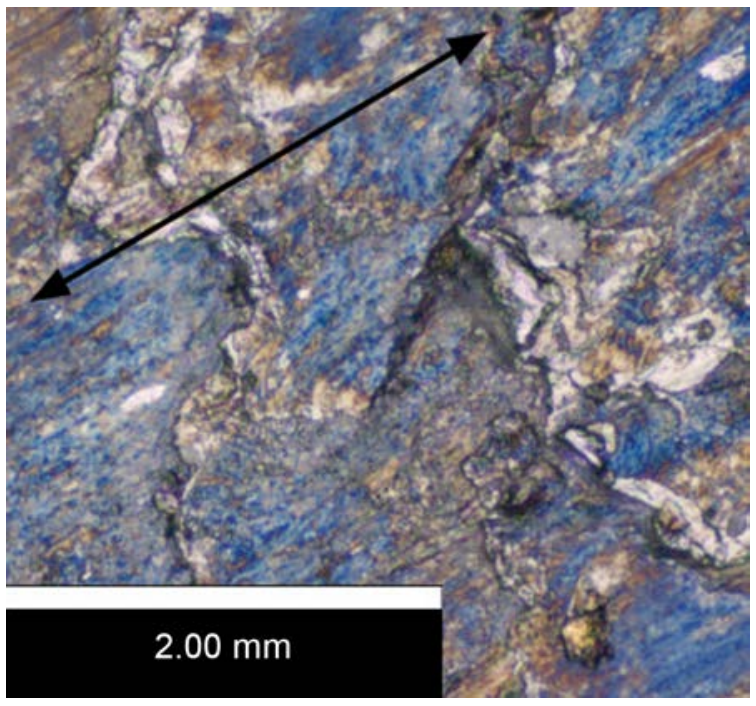

Figure 13 Optical image of cast iron mild-scuff

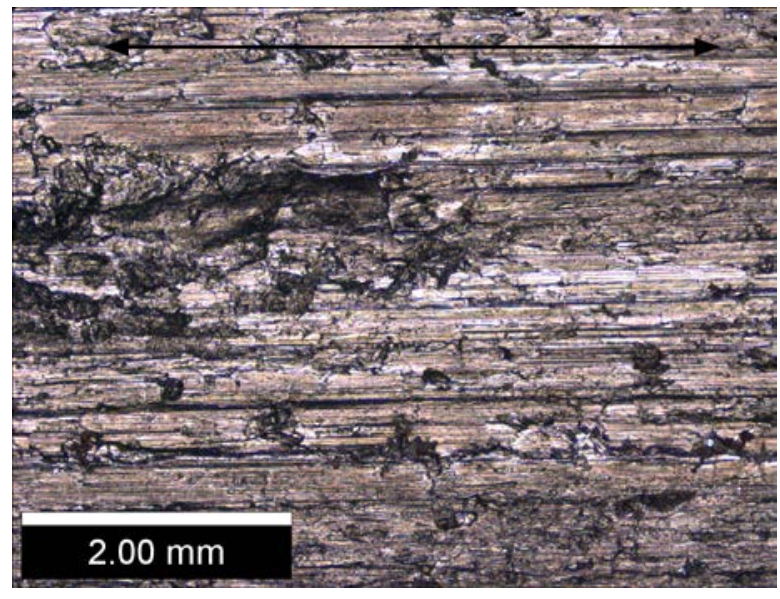

Figure 15 Optical image of cast iron severe-scuff

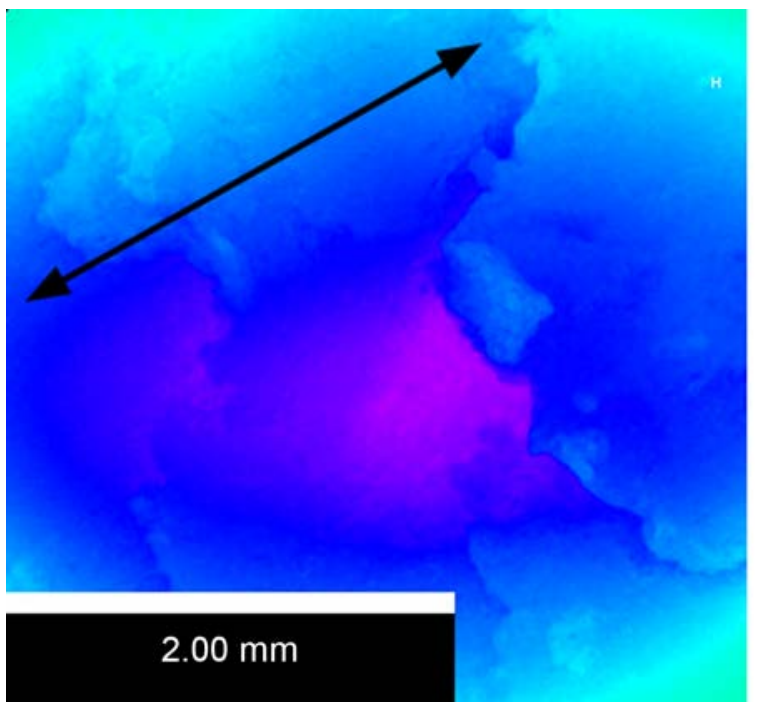

Figure 14 3D colour map of cast iron mild-scuff
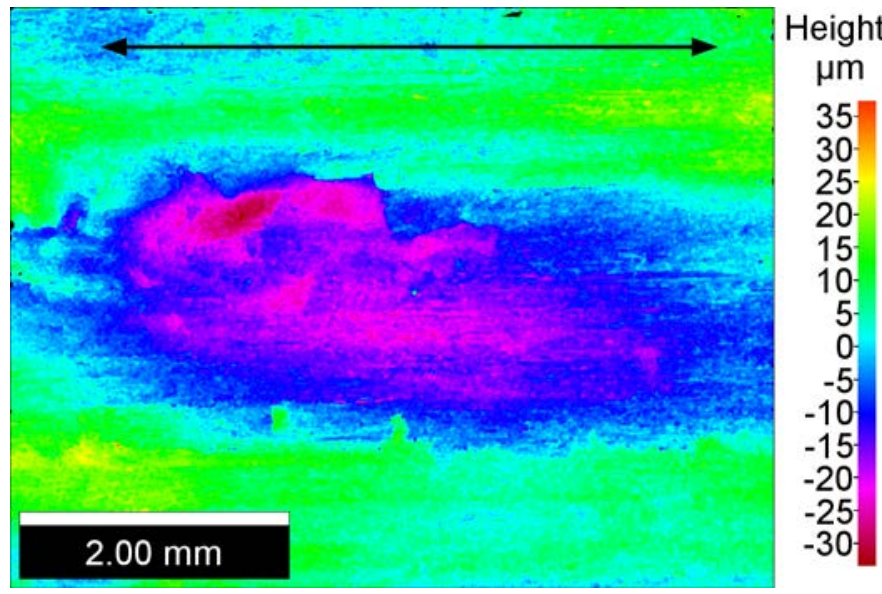

Figure 16 3D colour map of cast iron severe-scuff 


\subsubsection{Electron and ion beam microscopy}

Agglomeration of wear debris was observed at the end of the wear scar on the original ground surface, Figure 18. Figure 19 shows the mild scuff cast iron surface which was made from platelets of various sizes some of which are joined into large sheets approximately $50 \mu \mathrm{m}$ across. There were cracks in the surface separating some of the platelets; the edges of the cracks are raised from the surface. A FIB cross section was made transverse to the direction of reciprocation through the mild scuff cast iron wear scar, Figures 20 and 21. Two large cracks were visible, the first at the top of the image completely separates a region of material, $2 \mu \mathrm{m}$ in depth, which has a highly refined microstructure compared to the bulk matrix. The second crack arrested in the middle of the image at a region of high contrast. There were several regions of high contrast adjacent to the crack and these were surrounded by deformed matrix material. The microstructure in between the two cracks exhibited modest microstructural refinement. A longitudinal FIB cross-section identified two microstructural features of high contrast, Figures 22 and 23 . There was a spheroidal structure present at the right of the image, grains around it were deformed an elongated although no cracks were visible. On the left of the image was an angular inclusion which had a crack propagating from its tail edge. There were no cracks present in the matrix away from these features.

\subsubsection{Energy dispersive X-ray Spectroscopy}

Micro-structural features corresponding to dross features were identified on the polished cast iron cross section, Figure 24 . The dross inclusion had a composition of: $33.6 \% \mathrm{C}, 12.9 \% \mathrm{O}, 7.2 \% \mathrm{Mg}, 0.5 \% \mathrm{Si}, 0.4 \% \mathrm{P} 0.5 \% \mathrm{~S}$, $0.5 \% \mathrm{Mn}, 45.4 \% \mathrm{Fe}$, Table 2. EDS analysis of similar features on the FIB cross section revealed similar composition of carbon, oxygen and iron, however other elements were not detected.

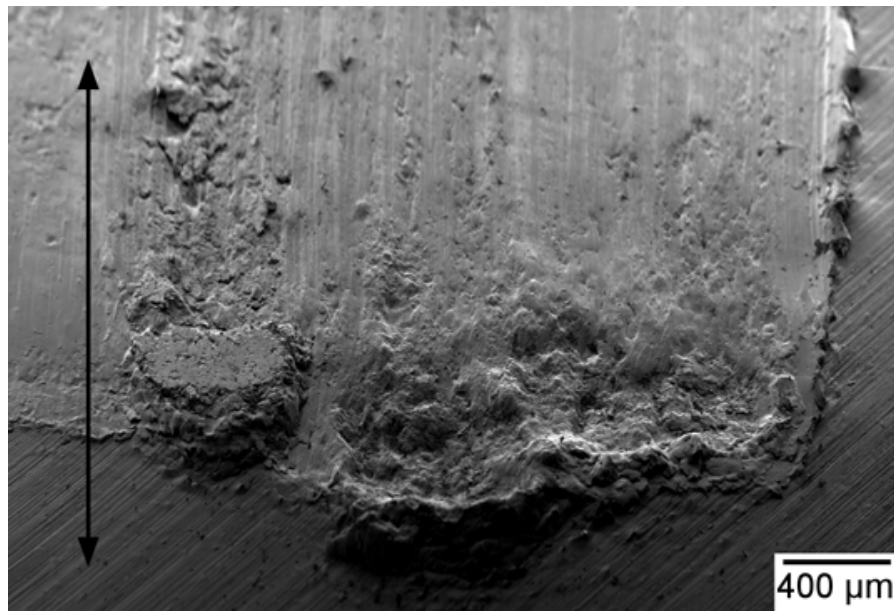

Figure 17 Debris agglomeration at the edge of the wear scar

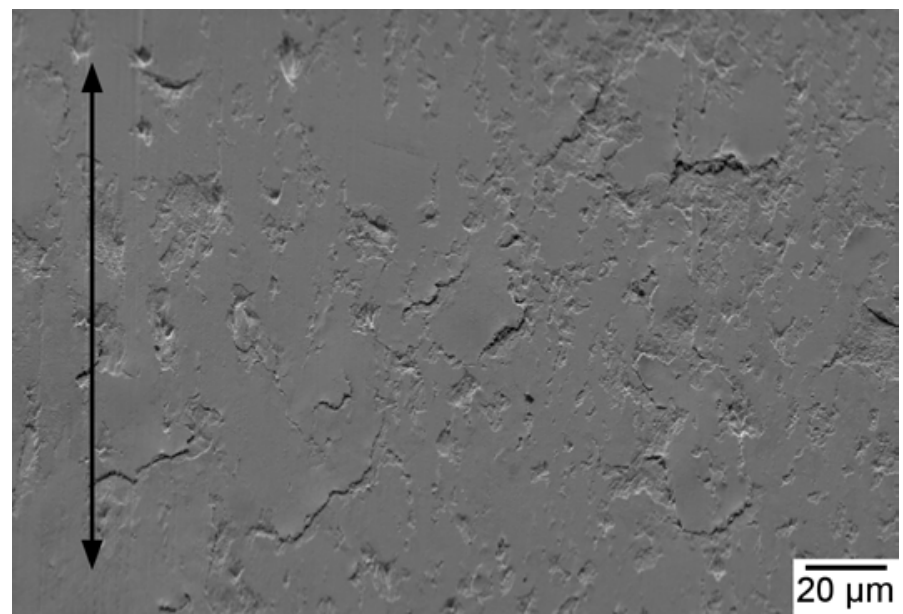

Figure 18 Mild-scuff surface 


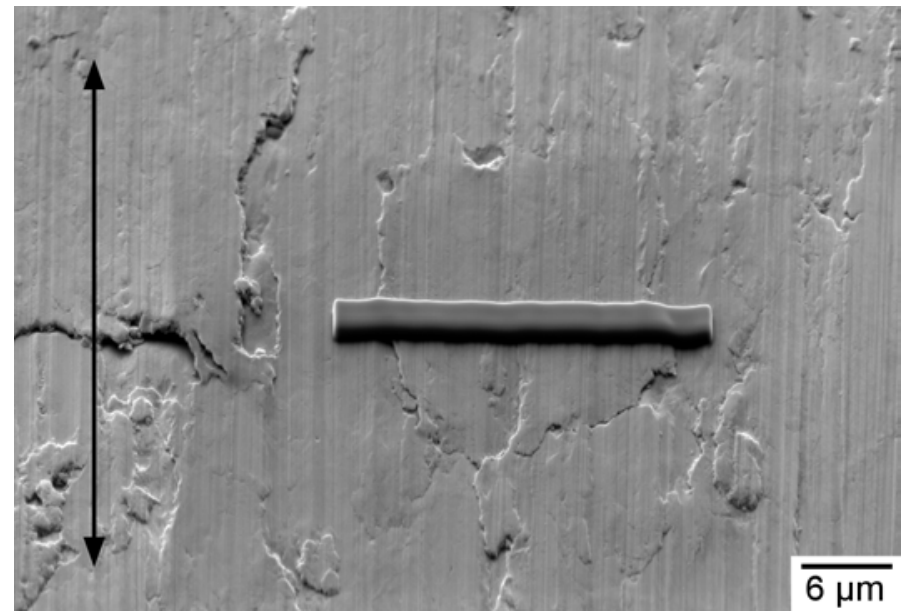

Figure 19 Area of interest on mild-scuffed surface for transverse cross-section

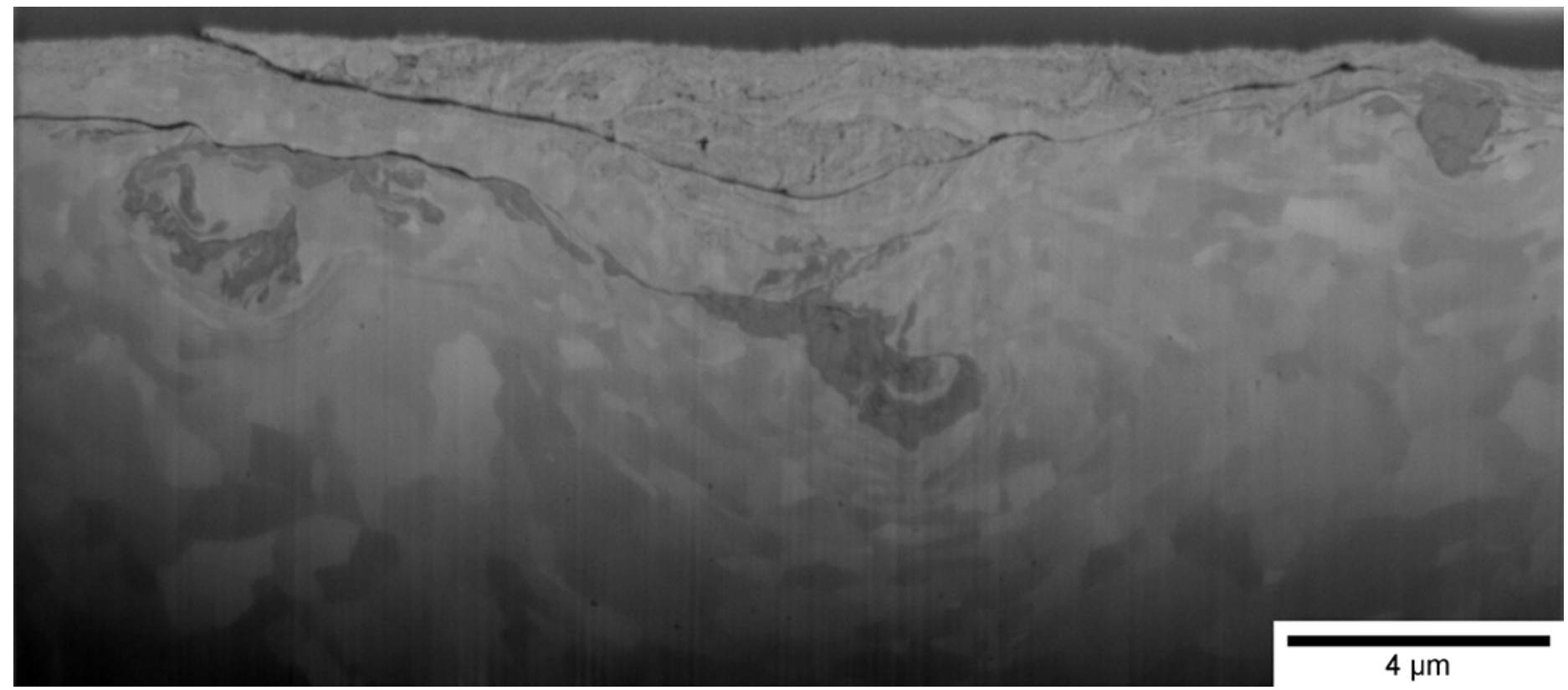

Figure 20 Secondary ion image of a focused ion beam transverse cross-section through the base of the mild-scuffed cast iron wear scar

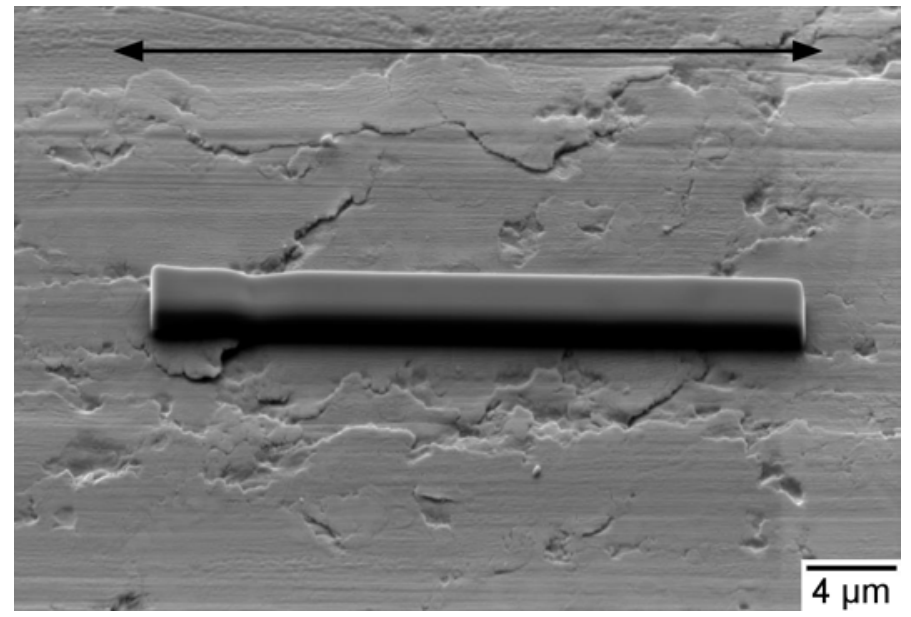

Figure 21 Area of interest on mild scuffed surface for longitudinal cross-section 


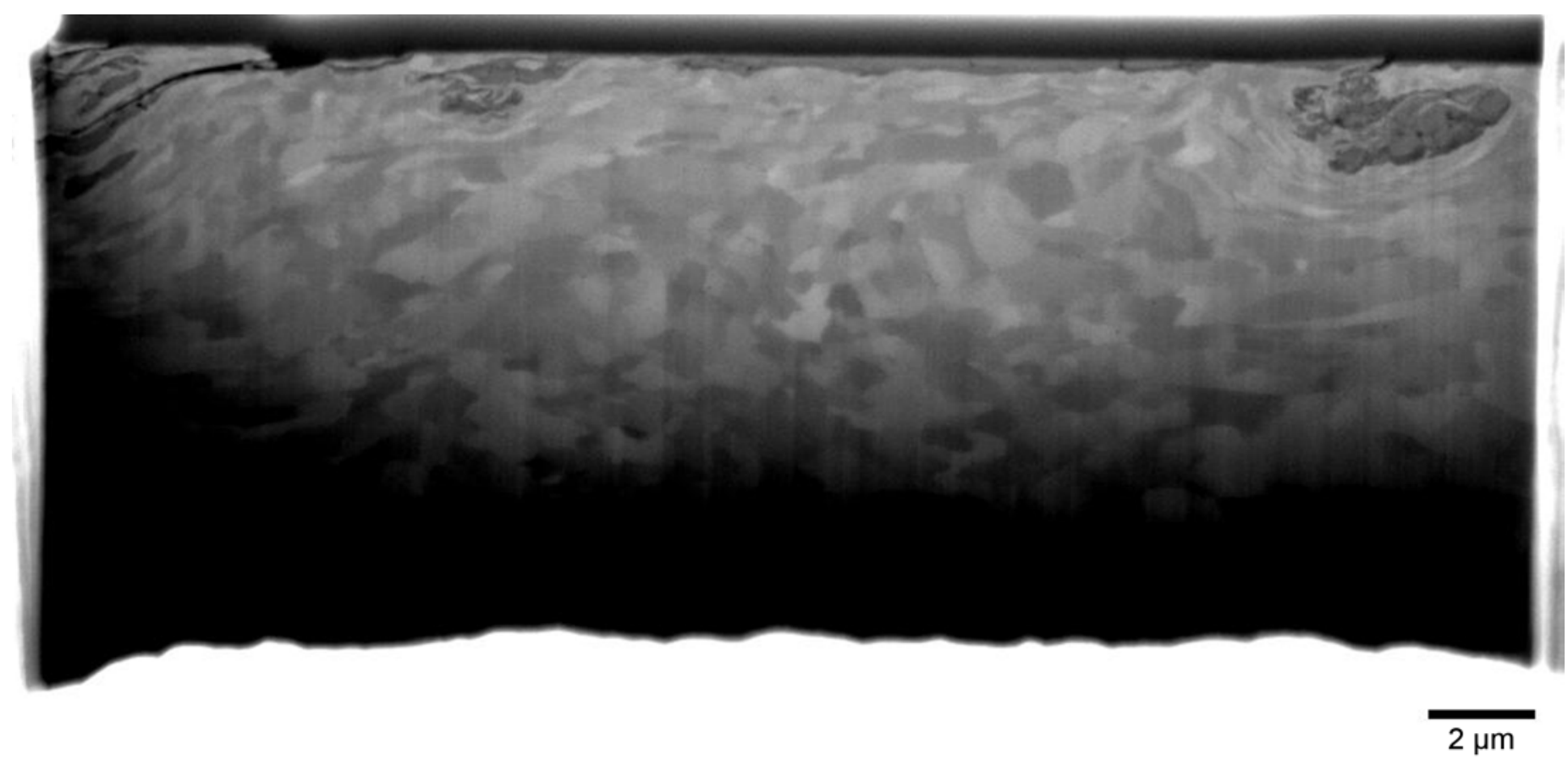

Figure 22 Secondary ion image of a focused ion beam longitudinal cross-section through the base of the mild-scuffed cast iron wear scar

\section{Discussion}

A good line contact between the roller bearing element and the spheroidal cast iron was achieved with no edge loading indicated by the rectangular wear scar, Figure 9. Parallel alignment between the surfaces in the reciprocating direction was evident by the symmetric high speed friction trace which was uniform over the stroke, Figure 8.

The progression of scuffing on the surfaces may be separated into three stages: running-in, mild-scuffing and severe-scuffing. Mild scuffing presents as localised damage which reduces the surface roughness, crucially it is possible that the contact might recover from this condition [17]. Severe scuffing however is irrecoverable and results in gross surface damage and a dramatic increase in roughness [12] due to significant adhesive wear of the cast iron surface causing catastrophic damage.

\subsection{Running in}

At the start of the running-in period the contact potential rose as asperities were quickly worn away producing a lubricated conformal contact. As the temperature increased to $100^{\circ} \mathrm{C}$ the lubricant viscosity decreased and the load carrying capacity of the film decreased. This was observed as a decrease in contact potential as more asperities came into contact and was also reflected by an increase in the average friction coefficient, Figure 6.

The high speed friction data took the form of a square wave which indicated that the friction response was independent from the sliding velocity, Figure 8 . The lack of hydrodynamic effects confirmed that the contact was operating in a boundary lubricated conditions. The close grouping of all the cycles indicated the contact was operating in a steady state condition, although the contact potential fluctuated between strokes. This was due to the running in process, which gradually wore surface asperities to create a conformal contact. The contact potential asymmetry was due to the lubricant feed position at the negative stroke end. 


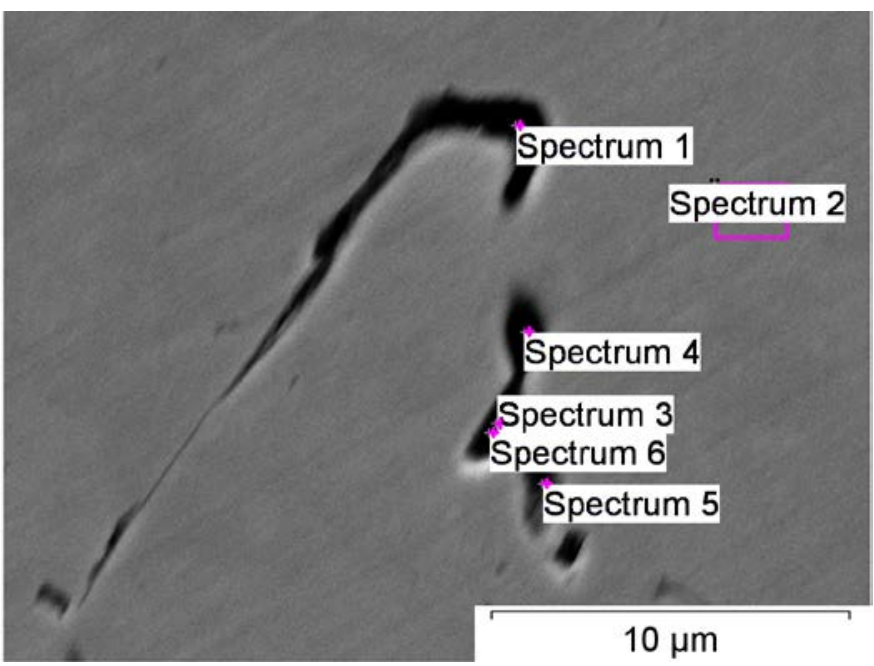

Figure 23 EDS analysis of spheroidal cast iron dross inclusions

\begin{tabular}{c|cccccccc}
\hline Spectrum & $\mathrm{C}$ & $\mathrm{O}$ & $\mathrm{Mg}$ & $\mathrm{Si}$ & $\mathrm{P}$ & $\mathrm{S}$ & $\mathrm{Mn}$ & $\mathrm{Fe}$ \\
\hline 1 & 32.57 & 12.85 & 7.20 & 0.53 & 0.44 & 0.49 & 0.50 & 45.42 \\
2 & 3.78 & 0.54 & 0.00 & 2.53 & 0.10 & 0.00 & 0.41 & 92.72 \\
3 & 6.04 & 1.96 & 0.32 & 1.34 & 0.29 & 0.27 & 1.23 & 88.55 \\
4 & 6.26 & 2.20 & 0.36 & 1.63 & 0.10 & 0.26 & 0.65 & 88.54 \\
5 & 4.59 & 2.21 & 0.78 & 1.54 & 0.37 & 0.16 & 0.85 & 89.50 \\
6 & 3.89 & 0.57 & 0.29 & 1.94 & 0.39 & 0.00 & 0.60 & 92.58 \\
\hline
\end{tabular}

Table 2 Weight \% composition of EDS spectra in Figure 24

The contact reached the operating temperature of $180^{\circ} \mathrm{C}$ at approximately $900 \mathrm{~s}$ which coincided with the maximum friction coefficient during both experiments, two different behaviours were subsequently observed, Figures 6 and 7. In experiment 1 the friction coefficient slowly decreased until the 200N load step (Figure 6), however in the second experiment it dropped rapidly to a local minimum of 0.07 before increasing up to a similar value to experiment 1 before the $200 \mathrm{~N}$ load step (Figure 7). It is thought that a temporary lubricous graphite tribofilm was formed on the surface of the cast iron in experiment 2 which did not form during experiment 1 . The difference may be due to the variations in the relative distribution of graphite in the cast iron samples.

\subsection{Mild scuffing}

During the load steps the friction coefficient decreased until severe scuffing occurred, Figures 6 and 7 . At the start of the final load step the high speed friction force indicated that a local increase had occurred in the decelerating direction at both stroke reversal positions, Figure 10. Interference between the roller bearing leading edge and the edge of the wear scar by debris could have been responsible as wear debris had accumulated on the ground surface outside the wear scar, Figure 18. The magnitude of the local increase in friction force was thought to be a measure of surface wear. An increase in excess of $100 \%$ of the RMS friction value was used as an indicator that mild scuffing was occurring. During mild scuffing there was little evidence of adhesive wear during the accelerating phase of the stroke reversal. The contact potential was close to zero across the whole stroke indicating continuous asperity contact.

The wear associated with mild scuffing smoothed the ground surface to an $R_{a}=0.294 \pm 0.014 \mu \mathrm{m}$, which is shown in Figure 13. The bearing area curves in Figure 4 show that material was removed from the asperity peaks and filled in some of the material valleys. This process was observed as precursor to severe scuffing by Suh et al, [17], [33]. Filmy wear debris formed during this process thought to be responsible for the increase in friction force, were observed by Akagaki et al [34]. The scanning electron image of the surface showed a smooth surface with small scoring marks in the reciprocating direction which agreed with the stylus profilometery, Figure 19.

At higher magnification cracks can been seen in the surface, Figure 19, which focused ion beam microscopy revealed to be of two different types, Figure 21. The uppermost was the interface between the original surface and severely deformed asperities which have been smeared across it. The crack was due to the poor adhesion of the deformed material which was likely to be coated in a nascent oxide layer and lubricant. The focused ion beam cross section also revealed the crack to originate at subsurface stress raises in the matrix, 
Figure 23 , however the size of the features was significantly smaller than the average spheroidal graphite colony. Direct chemical analysis using EDS techniques was difficult due to the interaction volume of the species below the surface. Thus the polished cross section of the un-deformed GJS400-15 material was examined for similar features, as shown in Figure 24.

Quantitative EDS analysis, Table 2, revealed a high concentration of magnesium, sulphur, manganese and oxygen suggesting that these features were dross inclusions formed during the casting process [35], [36], where incomplete nodularisation of the graphite had led to stringers resembling more of a flake structure. The features themselves appeared to have resisted plastic deformation induced by the normal load and shear forces from the reciprocating counter face, but facilitated plastic shear and cracking within the ferritic matrix at their interface, Figure 23. This was significant as it suggested that the onset of mild scuffing in spheroidal cast irons was similar to that observed in flake cast iron, where platelet formation and ultimately severe adhesive wear occurred by decohesion of a pearlitic matrix along flake graphite interfaces [17]. Features observed in the longitudinal cross section that were spherical appeared to avoid crack initiation, resulting rather in deformation of the ferritic matrix and a reduction in grain size. Thus the enhanced ductility of spheroidal cast iron for cylinder liner applications benefits scuffing resistance to the extent that the casting process has been controlled to avoid dross inclusions that compromise severe scuffing resistance.

\subsection{Severe scuffed surface}

The transition from mild to severe scuffing was captured during 15 cycles, over a period of 1 second at a load of $700 \mathrm{~N}$. During the transition to severe scuffing the friction force doubled at the stroke reversal positions in both the accelerating and decelerating directions and then at many of the locations throughout the stroke. This was due to the extenuation of the severe contact conditions at the stroke reversal positions resulting in higher energy asperity contact causing adhesive wear. The increase initially occurred at the opposite end to the lubrication feed where the contact conditions were most severe but subsequently propagated across the stroke as wear debris entrained in the contact disrupted the lubricant supply and caused locally high pressures to develop. The damage was most severe in the accelerating direction at the opposite end to the lubricant feed, due to the onset of adhesive wear. The contact potential remained close to zero during the scuffing transition as the surfaces were in continuous contact. Cracks which had initially formed around dross inclusions are likely to have subsequently grown through the matrix due to the high degree of plastic deformation, also reported by Abedi et al [21]. The extensive crack networks facilitated cast iron liner material to be removed in large sections up to $40 \mu \mathrm{m}$ deep by adhesive wear, which was similarly observed by Wojciechowski et al [20]. The severity of the adhesive wear produced an order of magnitude increase in surface roughness across the wear scar, $R_{a}=3.347 \pm 0.324 \mu \mathrm{m}$ [23], Figures 15 and 16. Large pieces of material which were entrained into the contact work hardened and caused scoring [23], [37], which prevented the lubricant film from recovering and resulted in increased scuffing wear, Figure 16.

Previous work on spheroidal cast iron scuffing failure has been focused on the role of graphite spheroids in the formation of a subsurface crack network, which permits material to be easily removed disrupting the lubricated contact causing scuffing [21], [26]. This work supports the growth of subsurface cracks as the mechanism for severe scuffing. However, through the use of focused ion beam cross-sectioning it has been possible to determine that cracks develop around dross stringers, resembling flake graphite, earlier in the wear process during mild scuffing. The formation of dross stringers involves elements which are well regulated in the casting process, consequently spheroidal cast iron has good severe scuffing resistance and potential suitability as a cylinder liner material. 


\section{Conclusions}

- High speed friction data was analysed to repeatedly (within $2 \%$ sliding distance) interrupt the onset of severe scuffing of EN-GJS 400-15 spheroidal graphite cast iron at normal load of $700 \mathrm{~N}$ by a reciprocating 52100 bearing steel.

- During mild scuffing the surface roughness was reduced by plastic deformation of the ferrite matrix. Wear debris formed during this process caused an increase in friction in the decelerating direction.

- The transition from mild to severe scuffing occurred at $700 \mathrm{~N}$ when sections of cast iron material, weakened by the growth crack networks through the matrix, were removed by adhesive wear.

- Wear particles quickly work hardened in the contact and produced scoring in the direction of reciprocation. The scuffed surface comprised on both scoring and scuffing damage which produced a very rough surface.

- Flake like dross inclusions cause initiation and propagation of cracks which appeared to be the material initiators for scuffing.

- The high speed friction data analysis presented has the potential to enhance the investigation of potential automotive ring-liner contacts by providing a greater insight into the scuffing mechanisms of material pairs by detecting the onset of mild scuffing and transition to severe scuffing.

\section{Acknowledgements}

Thanks to Pawee Kucita for assistance with SEM and EDS analysis. The authors acknowledge access to the Zeiss NVision40 FIB instrument at the Southampton Nanofabrication Centre.

\section{Data Access}

All data supporting this study are openly available from the University of Southampton repository at http://dx.doi.org/10.5258/SOTON/403226 


\section{References}

[1] V. W. Wong and S. C. Tung, "Overview of automotive engine friction and reduction trends-Effects of surface, material, and lubricant-additive technologies," Friction, vol. 4, no. 1, pp. 1-28, 2016.

[2] Y. Enomoto and T. Yamamoto, "New materials in automotive tribology," Tribol. Lett., vol. 5, pp. 1324, 1998.

[3] M. Priest and C. M. Taylor, "Automobile engine tribology - approaching the surface," Wear, vol. 241, no. 2, pp. 193-203, Jul. 2000.

[4] D. E. Richardson, "Review of Power Cylinder Friction for Diesel Engines," J. Eng. Gas Turbines Power, vol. 122, no. 4, pp. 506-519, 2000.

[5] K. Holmberg, P. Andersson, and A. Erdemir, "Global energy consumption due to friction in passenger cars," Tribol. Int., vol. 47, pp. 221-234, 2012.

[6] Y. Tateishi, "Tribological issues in reducing piston ring friction losses," Tribol. Int., vol. 27, no. 1, pp. 17-23, Feb. 1994.

[7] ASTM G40-15, Standard terminology relating to wear and erosion. West Conshohocken, PA: ASTM International, 2015.

[8] G. C. Barber and K. C. Ludema, "The break-in stage of cylinder-ring wear: a correlation between fired engines and a laboratory simulator," Wear, vol. 118, pp. 57-75, 1987.

[9] J. E. Booth, T. J. Harvey, R. J. K. Wood, and H. E. G. Powrie, "Scuffing detection of TU3 cam-follower contacts by electrostatic charge condition monitoring," Tribol. Int., vol. 43, no. 1-2, pp. 113-128, Jan. 2010.

[10] H. Rahnejat, Ed., Tribology and dynamics of engine and powertrain: Fundamental, applications and future trends. Cambridge: Woodhead Publishing Limited, 2010.

[11] M. Shuster, T. Stong, M. C. Deis, and D. C. Burke, "Piston ring cylinder liner scuffing phenomenon: Investigation, simulation and prevention," SAE Pap. 1999-01-1219, 1999.

[12] M. Shuster, D. Combs, K. Karrip, and D. Burke, "Piston ring cylinder liner scuffing phenomenon studies using acoustic emission technique," SAE Pap. 2000-01-1782, 2000.

[13] F. Saeidi, S. A. Shevchik, and K. Wasmer, "Automatic detection of scuffing using acoustic emission," Tribol. Int., vol. 94, pp. 112-117, 2016.

[14] O. D. Tasbaz, R. J. K. Wood, M. Browne, H. E. G. Powrie, and G. Denuault, "Electrostatic monitoring of oil lubricated sliding point contacts for early detection of scuffing," Wear, vol. 230, no. 1, pp. 86-97, May 1999.

[15] S. Morris, R. J. K. Wood, T. J. Harvey, and H. E. G. Powrie, "Use of electrostatic charge monitoring for early detection of adhesive wear in oil lubricated contacts," J. Tribol., vol. 124, no. 2, pp. 288-296, 2002.

[16] J. Qu, J. J. Truhan, and P. J. Blau, "Investigation of the scuffing characteristics of candidate materials for heavy duty diesel fuel injectors," Tribol. Int., vol. 38, pp. 381-390, 2005.

[17] T. J. Kamps, J. C. Walker, R. J. Wood, P. M. Lee, and A. G. Plint, "Reproducing automotive engine scuffing using a lubricated reciprocating contact," Wear, vol. 332-333, pp. 1193-1199, 2015.

[18] A. R. Riahi and A. T. Alpas, "Wear map for grey cast iron," Wear, vol. 255, no. 1-6, pp. 401-409, 2003. 
[19] E. D. Rejowski, E. Soares, I. Roth, and S. Rudolph, "Cylinder Liner in Ductile Cast Iron for High Loaded Combustion Diesel Engines," J. Eng. Gas Turbines Power, vol. 134, p. 72807, 2012.

[20] Ł. Wojciechowski, S. Eymard, Z. Ignaszak, and T. G. Mathia, "Fundamentals of ductile cast iron scuffing at the boundary lubrication regime," Tribol. Int., vol. 90, pp. 445-454, Oct. 2015.

[21] H. R. Abedi, A. Fareghi, H. Saghafian, and S. H. Kheirandish, "Sliding wear behavior of a ferriticpearlitic ductile cast iron with different nodule count," Wear, vol. 268, pp. 622-628, 2010.

[22] D. Stickel and A. Fischer, "The influence of topography on the specific dissipated friction power in ultra-mild sliding wear: Experiment and simulation," Tribol. Int., vol. 91, pp. 48-59, 2015.

[23] B. K. Prasad, "Sliding wear response of cast iron as influenced by microstructural features and test condition," Mater. Sci. Eng. A, vol. 456, pp. 373-385, 2007.

[24] J. Sugishita and S. Fujiyoshi, "The effect of cast iron graphites on friction and wear performance I: Graphite film formation on grey cast iron surfaces," Wear, vol. 66, pp. 209-221, 1981.

[25] J. M. Han, R. Zhang, O. O. Ajayi, G. C. Barber, Q. Zou, L. Guessous, D. Schall, and S. Alnabulsi, "Scuffing behavior of gray iron and 1080 steel in reciprocating and rotational sliding," Wear, vol. 271, pp. 1854$1861,2011$.

[26] R. S. Montgomery, "The mild wear mechanism of nodular iron," Wear, vol. 13, pp. 337-343, 1969.

[27] V. K. Jha, Y. H. Mozumder, S. Shama, R. K. Behera, A. Pattaniak, L. P. Sindhoora, S. C. Mishra, and S. Sen, "Dry sliding wear system response of ferritic and tempered martensitic ductile iron," IOP Conf. Ser. Mater. Sci. Eng., vol. 75, p. 12009, 2015.

[28] P. S. Gupte, Y. Wang, W. Miller, G. C. Barber, C. Yao, B. Zhou, and Q. Zou, "A study of torn and folded metal (TFM) on honed cylinder bore surfaces," Tribol. Trans., vol. 51, pp. 784-789, 2008.

[29] Y. Wang and S. C. Tung, "Scuffing and wear behavior of aluminum piston skirt coatings against aluminum cylinder bore," Wear, vol. 225-229, pp. 1100-1108, 1999.

[30] Y. Wang, K. Brogan, and S. C. Tung, "Wear and scuffing characteristics of composite polymer and nickel/ceramic composite coated piston skirts against aluminum and cast iron cylinder bores," Wear, vol. 250, pp. 706-717, 2001.

[31] K. Liu, X. J. Liu, and C. L. Gui, "Scuffing failure analysis and experimental simulation of piston ring cylinder liner," Tribol. Lett., vol. 5, pp. 309-312, 1998.

[32] C. A. Schneider, W. S. Rasband, and K. W. Eliceiri, "NIH Image to ImageJ: 25 years of image analysis," Nat. Methods, vol. 9, no. 7, pp. 671-675, 2012.

[33] A. Y. Suh, A. A. Polycarpou, and T. F. Conry, "Detailed surface roughness characterization of engineering surfaces undergoing tribological testing leading to scuffing," Wear, vol. 255, pp. 556-568, 2003.

[34] T. Akagaki and K. Kato, "Plastic flow process of surface layers in flow wear under boundary lubricated conditions," Wear, vol. 117, pp. 179-196, 1987.

[35] G. M. Goodrich, "Cast Iron Microstructure Anomalies and Their Causes," AFS Trans., pp. 669-683, 1997.

[36] M. Gagné, M. Paquin, and P. Cabanne, "Dross in Ductile Iron : Source , Formation and Explanation," Foundry Trade J., pp. 276-280, 2009.

[37] B. K. Prasad, "Sliding wear behaviour of a cast iron as affected by test environment and applied load," Ind. Lubr. Tribol., vol. 61, no. 3, pp. 161-172, 2014. 